\title{
Successful hematopoietic stem cell transplantation after myeloablative conditioning in three patients with dedicator of cytokinesis 8 deficiency (DOCK8) related Hyper IgE syndrome
}

\author{
Barış Kuşkonmaz $\mathbb{D}^{1} \cdot$ Deniz Ayvaz $^{2} \cdot$ İlhan Tezcan ${ }^{2} \cdot$ Aysel Yüce $^{3} \cdot$ Özden Sanal $^{2} \cdot$ Duygu Uçkan Çetinkaya $^{1}$
}

Received: 23 March 2017 / Revised: 11 November 2017 / Accepted: 19 November 2017 / Published online: 21 December 2017

(c) Macmillan Publishers Limited, part of Springer Nature 2018

Dedicator of cytokinesis 8 (DOCK8) deficiency is an autosomal-recessive form of hyperimmunoglobulin E syndrome which is a primary immunodeficiency (PID), also classified in the group of combined immunodeficiencies [1]. DOCK8 is a protein within the family of Rho-GTPases which is expressed in lymphocytes, affects cell signaling and reorganization of the cytoskeleton [2]. Clinical features of this disease include recurrent upper and lower respiratory tract infections, elevated IgE levels, eosinophilia, severe atopic dermatitis, asthma, and food allergies. Patients with DOCK8 deficiency have increased incidence of viral cutaneous infection; herpes simplex virus, human papilloma virus, and molluscum contagiosum virus. A high risk of malignancy, which is typically hematologic or epithelial, are reported in $8-17 \%$ of patients with DOCK8 deficiency [3]. The only definitive treatment option is allogeneic hematopoietic stem cell transplantation (HSCT) and experience about HSCT in DOCK8 deficiency is limited [4, 5]. Here we report three cases with DOCK8 deficiency who underwent HSCT after myeloablative conditioning in our center.

The patients presented characteristic manifestations of DOCK8 deficiency including eczema (all patients), recurrent sinopulmonary infection (all patients), food allergy (Case 1,3). In case $1 \mathrm{IgE}$ specific for food allergens were as

Barış Kuşkonmaz

bkuskonmaz@gmail.com

1 Faculty of Medicine, Department of Pediatrics, Division of Bone Marrow Transplantation Unit, Hacettepe University, Sihhiye 06100 Ankara, Turkey

2 Faculty of Medicine, Department of Pediatrics, Division of Immunology, Hacettepe University, Sihhiye 06100 Ankara, Turkey

3 Faculty of Medicine, Department of Pediatrics, Division of Gastroenterology, Hepatology and Nutrition, Hacettepe University, Sihhiye 06100 Ankara, Turkey follows; egg white: $33.4 \mathrm{Ku} / \mathrm{L}$ (class 4), milk: $37.6 \mathrm{Ku} / \mathrm{L}$ (class 4) and nuts: $22.8 \mathrm{Ku} / \mathrm{L}$ (class 4 ). In case 3 food mix test showed $24.4 \mathrm{Ku} / \mathrm{L}$ (class 4). Case 3 also had molluscum contagiosum. Additionally, case 2 had resistant giardiasis, sclerosing cholangitis and colitis and case 3 had sclerosing cholangitis. Cryptosporidium was not isolated in the patients with sclerosing cholangitis. Case 3 also had bronchiectasis before HSCT. All three cases were given monthly intravenous immunoglobulin therapy and trimethoprim-sulfomethaxozole prophylaxis. In addition to the clinical features compatible with DOCK8 deficiency, diagnosis was also confirmed with mutational analysis. The details of the mutations are given in the table as given in Table 2.

The donors were human leukocyte antigen (HLA) identical siblings in all patients. Busulfan based myeloablative conditioning regimen was used (Table 1). Cyclosporine A and short-course methotrexate on days $+1,+3,+6$ were used as graft versus host disease prophylaxis in all patients (Table 1).

Engraftment was achieved in all patients. The chimerism analysis showed $93 \%$ donor profile in case 1 (with full donor chimerism at follow up) and full donor chimerism (donor chimerism $>\% 95$ ) in other two cases at +1 month after HSCT. None of the patients developed acute or chronic GVHD. After HSCT case 2 developed hyperbilirubinemia $[5.28 \mathrm{mg} / \mathrm{dl}(0.3-1.2 \mathrm{mg} / \mathrm{dl}))]$, high transaminase levels [ALT: $544 \mathrm{U} / \mathrm{L}(<39 \mathrm{U} / \mathrm{L})$, AST: $337(<51 \mathrm{U} / \mathrm{L})$ ], hypoalbuminemia $[3.1 \mathrm{~g} / \mathrm{dL}(3.5-5.2 \mathrm{~g} / \mathrm{dL})]$, painful hepatomegaly, edema, oliguria, and weight gain ( $>5 \%$ from baseline). Although a late finding, a decreased or reversed portal venous flow was not shown on Doppler ultrasound. With these clinical and laboratory findings case 2 was diagnosed with VOD (moderate) which improved with defibrotide therapy.

Eczema resolved in all patients. Food allergy resolved clinically in both case 1 and case 3 . In case 1 specific Ig E 
Table 1 Transplant characteristics and outcome of patients

\begin{tabular}{|c|c|c|c|}
\hline & Case 1 & Case 2 & Case 3 \\
\hline Age at $\operatorname{HSCT}(\mathrm{y})$ & 1.5 & 15.8 & 6.8 \\
\hline $\begin{array}{l}\text { Duration between diagnosis and } \\
\text { transplantation }\end{array}$ & $14 \mathrm{mo}$ & $12 \mathrm{mo}$ & $15 \mathrm{mo}$ \\
\hline Donor characteristics & $\begin{array}{l}\text { HLA identical } \\
\text { sibling }\end{array}$ & $\begin{array}{l}\text { HLA identical } \\
\text { sibling }\end{array}$ & $\begin{array}{l}\text { HLA identical } \\
\text { sibling }\end{array}$ \\
\hline \multirow[t]{2}{*}{ Conditioning regimen } & $\mathrm{Bu}(16 \mathrm{mg} / \mathrm{kg})$ & $\mathrm{Bu}(12.8 \mathrm{mg} / \mathrm{kg})$ & $\mathrm{Bu}(16 \mathrm{mg} / \mathrm{kg})$ \\
\hline & Cy $(200 \mathrm{mg} / \mathrm{kg})$ & Cy $(200$ mg/kg) & Cy $(200 \mathrm{mg} / \mathrm{kg})$ \\
\hline GVHD prophylaxis & $\mathrm{CsA}+\mathrm{MTX}$ & $\mathrm{CsA}+\mathrm{MTX}$ & $\mathrm{CsA}+\mathrm{MTX}$ \\
\hline Source of stem cell & $\mathrm{BM}$ & $\mathrm{BM}$ & $\mathrm{BM}$ \\
\hline The number of $\mathrm{CD} 34^{+}$cells & $3.7 \times 10^{6} / \mathrm{kg}$ & $3.3 \times 10^{6} / \mathrm{kg}$ & $3.6 \times 10^{6} / \mathrm{kg}$ \\
\hline $\begin{array}{l}\text { Day of neutrophil and thrombocyte } \\
\text { engraftment }\end{array}$ & $12 / 36$ & $14 / 25$ & $14 / 25$ \\
\hline GVHD & - & - & - \\
\hline VOD & - & + & - \\
\hline
\end{tabular}

HSCT hematopoietic stem cell transplantation, $y$ year, mo months, $M$ male, $F$ female, $B M$ bone marrow, $B u$ busulfan, $C y$ cyclophosphamide, $G V H D$ graft versus host disease, $C s A$ cyclosporine A, MTX methotrexate, $V O D$ venoocclusive disease levels for egg white: $0.28 \mathrm{Ku} / \mathrm{L}$ (class 0 ), milk: $0.2 \mathrm{Ku} / \mathrm{L}$ (class 0) and nuts: $0.05 \mathrm{Ku} / \mathrm{L}$ (class 0) after HSCT (+72 months). In case 3 specific Ig E levels for egg white: $0.97 \mathrm{Ku} / \mathrm{L}$ (class 2), milk: $0.16 \mathrm{Ku} / \mathrm{L}$ (class 0 ) and nuts: $0.02 \mathrm{Ku} / \mathrm{L}$ (class 0$)$ after HSCT (+15 months). Sinopulmonary infections were significantly improved in all patients. Disseminated molluscum contagiosum infection recovered completely after HSCT in case 3. Liver function tests were within normal limits at long term follow-up in cases with sclerosing cholangitis (case 2 and 3). This may be associated with the recovery of underlying immunologic dysfunction after HSCT. In case 2, findings related to colitis disappeared completely after HSCT. This may be associated with the recovery of underlying immunologic dysfunction after HSCT. No pulmonary complications or worsening of pulmonary findings were observed after HSCT in case 3 with bronchiectasis.

The details of immunologic parameters of the patients are shown in Table 2. Eosinophilia (normal: $40-360 / \mathrm{mm}^{3}$ ) resolved significantly in +3 months and approached normal levels. Low IgM levels are increased, in all but one (patient 1) are normalized. High IgE levels (normal: 0-90 IU/ml) resolved significantly within 6 months after HSCT. In case 3 , IgE values were slightly elevated at last follow-up visit $(227 \mathrm{IU} / \mathrm{ml}$ at +3.5 th year at last follow-up visit). Increase in $\mathrm{CD} 4^{+} \mathrm{T}$ cells percentages and numbers were observed in all patients.

All patients are alive now with full donor chimerism and are off of immunoglobulin substitution. Disease free survival time is 72,64 , and 51 months in cases 1,2 , and 3 respectively.
HSCT represents the only curative therapy in patients with DOCK8 deficiency, and should be considered as early as possible before development of significant organ damage, life-threatening infections or malignancies $[4,5]$. It was suggested that even patients with significant comorbidities should undergo HSCT after these conditions are treated aggressively [5]. Optimal conditioning regimen for HSCT in PID has yet to be defined [5]. Reduced intensity conditioning regimen might be a reasonable option for most patients due to significant pre-transplant morbidity. However, there is also a very high rate of viral reactivation as part of reduced intensity conditioning regimen [4]. The conditioning regimen to be used in DOCK8 deficiency is also a matter of debate. A variety of conditioning regimens with different donor sources were used in different studies with varying success [4-7]. Many patients with DOCK8 deficiency have organ damage necessitating reducedintensity conditioning approaches, which in turn carry a higher risk of mixed donor chimerism [5]. In the study by Cuellar-Rodriguez et al. [4], in which six patients with DOCK8 deficiency were involved, myeloablative conditioning regimen consisting of busulfan and fludarabine was used. They reported that all patients had rapid engraftment with high levels of donor chimerism with minimal regimen related toxicity [4]. Al Herz et al. [5] reported results of HSCT in 11 patients with DOCK8 deficiency. Nine patients had received busulfan-based regimens combined either with cyclophosphamide or fludarabine- together with ATG in two patients. The remaining two patients had received a reduced-intensity conditioning regimen, fludarabine, melphalan, and alemtuzumab and these patients are reported to have mixed chimerism. 


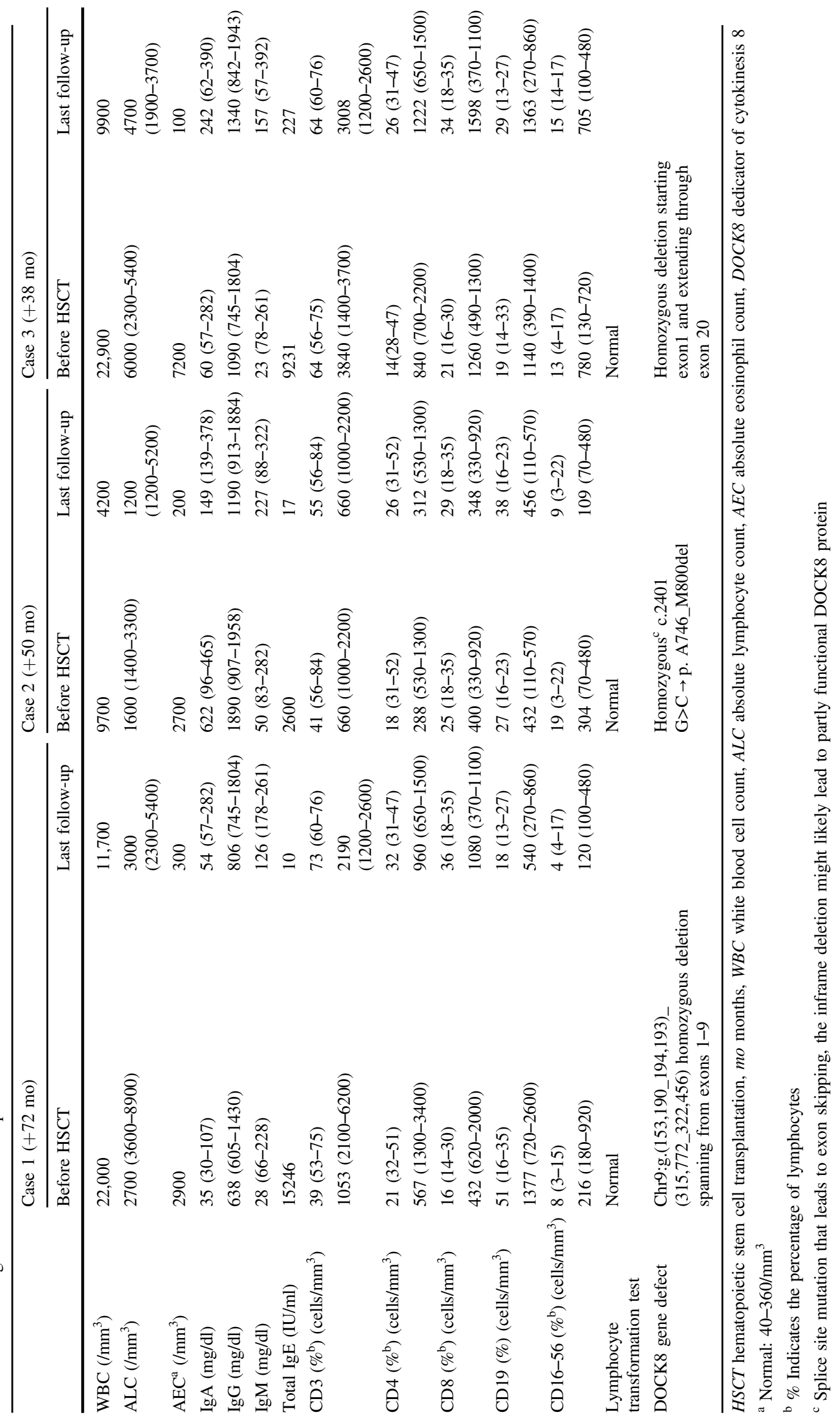


Another patient who had received a myeloablative dose of busulfan also had mixed chimerism in this series. The authors stated that; as all three patients with mixed chimerism received a mismatched unrelated graft, HLA mismatch might also have played a role [5]. In our study, three patients received a myeloablative regimen consisting of busulfan and cyclophosphamide and all donors were HLA identical siblings. Engraftment with full donor chimerism and a long term disease free survival were achieved in all these three patients.

In the series by Cuellar-Rodriguez et al. [4], all clinical manifestations of DOCK8 deficiency resolved posttransplant. In this series, the authors reported that the clinical correction correlated with the laboratory evidence of decreased IgE levels and eosinophils, along with a lymphocyte profile consistent with a new immunologic equipoise [4]. In the study by Al-Herz et al. [5], the clinical and immunologic parameters were improved significantly after HSCT. Ig E was reported to remain high in three patients. The authors speculated that high Ig E levels were related to ongoing infections [5]. In our study, we observed a significant improvement in clinical findings including eczema, sinopulmonary infections, food allergy, and molluscum contagiosum. We also detected improvement in the other immunologic parameters such as eosinophilia, low IgM, high IgE, and low $\mathrm{CD}^{+}{ }^{+} \mathrm{T}$ cell count before HSCT as seen in Table 2, progressively normalized after HSCT.

Sclerosing cholangitis is a relatively common finding in patients with DOCK8 deficiency [8]. Al-Herz et al. reported cryptosporidium species-induced sclerosing cholangitis in one of the eleven patients with DOCK8 deficieny underwent HSCT [5]. Chronic infection with Cryptosporidium is associated with sclerosing cholangitis in other primary immunodeficiencies with $\mathrm{CD} 4^{+}$lymphopenia or dysfunctional $\mathrm{CD}^{+}$lymphocytes $[9,10]$. Case 2 and case 3 had sclerosing cholangitis before HSCT. Cryptosporidium species were not isolated in these patients. Laboratory features of the sclerosing cholangitis resolved progressively after the HSCT. It may be because of the decreased inflammation firstly because of the conditioning regimen then because of the immunosuppressives used.

PIDs have been associated with a broad clinical spectrum of autoimmune gastrointestinal disorders including gastritis (pernicious anemia), celiac disease, autoimmune enteropathy, and inflammatory bowel disease [11]. In the background of frequent infections (e.g., Giardia, Campylobacter, Salmonella, rotavirus, enterovirus, and norovirus), diagnosis of nonspecific gastrointestinal symptoms such as nausea, vomiting, diarrhea, and weight loss becomes particularly challenging [12]. Gastrointestinal disorders are rarely reported in DOCK8 deficiency. Dinwiddie et al. [13]. reported intractable diarrhea, eczema, and infections in three brothers with DOCK8 deficiency. Case 2 in our series was previously reported as colitis associated with DOCK8 deficency in a study by Sanal et al. [14].

Ten of the eleven patients (91\%) were reported to be alive after HSCT in the study by Al-Herz et al. [5]. The authors suggest that this success is owed to their young age, early identification of several cases based on family history, and aggressive pre-HSCT management, including liver transplantation in one patient. Cuellar-Rodriguez et al. reported that all six patients in their series were alive [4]. A long term disease free survival was obtained in our patients.

In patients who lack a matched related or unrelated donor haploidentical bone marrow transplantation is described for DOCK8 deficiency by Shah et al. in a recent study. The authors reported that six of seven patients are alive and disease free in a median follow up time of 20.6 months [15].

DOCK8 protein has not been analyzed in immune cells in any of the patients and that this is a limitation for our study.

In conclusion, HSCT is the only curative therapy which provides resolution of clinical findings in DOCK8 deficiency. As soon as the patients get the diagnosis, HSCT should be planned in the earliest convenience. Myeloablative regimen can be used even in patients with disease related complications like bronchiectasis, sclerosing cholangitis, and colitis. Myeloablative conditioning also provides sustained full donor chimerism.

Acknowledgements The authors are very grateful to Helen $\mathrm{Su}$ (National Institutes of Health) and Talal Chatila (Harvard University) for the analysis of Dock8 gene. We thank the patients and their families for participation in this study.

\section{Compliance with ethical standards}

Conflict of interest The authors declare that they have no conflict of interest.

\section{References}

1. Al-Herz W, Bousfiha A, Casanova JL, Chapel H, Conley ME, Cunningham-Rundles $\mathrm{C}$, et al. Primary immunodeficiency diseases: an update on the classification from the international union of immunological societies expert committee for primary immunodeficiency. Front Immunol. 2011;2:54.

2. Ruusala A, Aspenstrom P. Isolation and characterisation of DOCK8, a member of the DOCK180-related regulators of cell morphology. FEBS Lett. 2004;572:159-66.

3. Aydin SE, Kilic SS, Aytekin C, Kumar A, Porras O, Kainulainen L, et al. DOCK8 deficiency: clinical and immunological phenotype and treatment options-a review of 136 patients. J Clin Immunol. 2015;35:189-98.

4. Cuellar-Rodriguez J, Freeman AF, Grossman J, Su H, Parta M, Murdock H, et al. Matched related and unrelated donor hematopoietic stem cell transplantation for DOCK8 deficiency. Biol Blood Marrow Transplant. 2015;21:1037-45. 
5. Al-Herz W, Chu JI, van der Spek J, Raghupathy R, Massaad MJ, Keles S, et al. Hematopoietic stem cell transplantation outcomes for 11 patients with dedicator of cytokinesis 8 deficiency. J Allergy Clin Immunol. 2016;138:852-9.

6. Metin A, Tavil B, Azık F, Isik P, Metin A, Emir S, et al. Successful bone marrow transplantation for DOCK8 deficient hyper IgE syndrome. Pediatr Transplant. 2012;16:398-9.

7. Boztug H, Karitnig-Weiss C, Ausserer B, Renner ED, Albert MH, Sawalle-Belohradsky $\mathrm{J}$, et al. Clinical and immunological correction of DOCK8 deficiency by allogeneic hematopoietic stem cell transplantation following a reduced toxicity conditioning regimen. Pediatr Hematol Oncol. 2012;29: 585-94.

8. Shah T, Cale C, Hadzic N, Jones A. Dedicator of cytokinesis 8 deficiency: a predisposition to sclerosing cholangitis. Clin Immunol. 2014;155:71-3.

9. Klein C, Lisowska-Grospierre B, LeDeist F, Fischer A, Griscelli C. Major histocompatibility complex class II deficiency: clinical manifestations, immunologic features, and outcome. J Pediatr. 1993;123:921-8.
10. Rodrigues F, Davies EG, Harrison P, McLauchlin J, Karani J, Portmann B, et al. Liver disease in children with primary immunodeficiencies. J Pediatr. 2004;145:333-9.

11. Agarwal S, Mayer L. Diagnosis and treatment of gastrointestinal disorders in patients with primary immunodeficiency. Clin Gastroenterol Hepatol. 2013;11:1050-63.

12. Walter JE, Farmer JR, Foldvari Z, Torgerson TR, Cooper MA. Mechanism-based strategies for the management of autoimmunity and immune dysregulation in primary immunodeficiencies. $\mathrm{J}$ Allergy Clin Immunol Pract. 2016;4:1089-100.

13. Dinwiddie DL, Kingsmore SF, Caracciolo S, Rossi G, Moratto D, Mazza C, et al. Combined DOCK8 and CLEC7A mutations causing immunodeficiency in 3 brothers with diarrhea, eczema, and infections. J Allergy Clin Immunol. 2013;131:594-7.

14. Sanal O, Jing H, Ozgur T, Ayvaz D, Strauss-Albee DM, ErsoyEvans S, et al. Additional diverse findings expand the clinical presentation of DOCK8 deficiency. J Clin Immunol. 2012;32:698-708.

15. Shah NN, Freeman AF, Su H, Cole K, Parta M, Moutsopoulos $\mathrm{NM}$, et al. Haploidentical related donor hematopoietic stem cell transplantation for dedicator-of-cytokinesis 8 deficiency using post-transplantation cyclophosphamide. Biol Blood Marrow Transplant. 2017;23:980-90. 